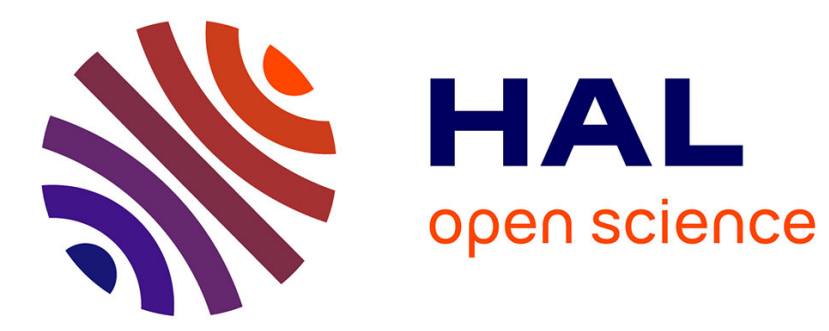

\title{
In-situ particle sizing at millimeter scale from electrochemical noise: simulation and experiments
}

Nour Eddin Yakdi, François Huet, Kieu Ngo

\section{To cite this version:}

Nour Eddin Yakdi, François Huet, Kieu Ngo. In-situ particle sizing at millimeter scale from electrochemical noise: simulation and experiments. Electrochimica Acta, 2015, 180, pp.1050-1058. 10.1016/j.electacta.2015.09.051 . hal-01253891

\section{HAL Id: hal-01253891 \\ https://hal.sorbonne-universite.fr/hal-01253891}

Submitted on 12 Jan 2016

HAL is a multi-disciplinary open access archive for the deposit and dissemination of scientific research documents, whether they are published or not. The documents may come from teaching and research institutions in France or abroad, or from public or private research centers.
L'archive ouverte pluridisciplinaire HAL, est destinée au dépôt et à la diffusion de documents scientifiques de niveau recherche, publiés ou non, émanant des établissements d'enseignement et de recherche français ou étrangers, des laboratoires publics ou privés. 


\title{
In-situ particle sizing at millimeter scale from electrochemical noise: simulation and experiments
}

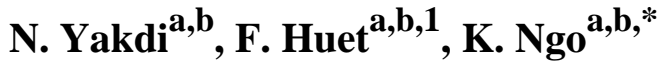 \\ ${ }^{a}$ Sorbonne Universités, UPMC Univ Paris 06, UMR 8235, Laboratoire Interfaces et Systèmes \\ Electrochimiques, F-75005, Paris, France \\ ${ }^{b}$ CNRS, UMR 8235, LISE, F-75005, Paris, France
}

\begin{abstract}
Over the last few years, particle sizing techniques in multiphase flows based on optical technologies emerged as standard tools but the main disadvantage of these techniques is their dependence on the visibility of the measurement volume and on the focal distance. Thus, it is important to promote alternative techniques for particle sizing, and, moreover, able to work in hostile environment. This paper presents a single-particle sizing technique at a millimeter scale based on the measurement of the variation of the electrolyte resistance (ER) due to the passage of an insulating sphere between two electrodes immerged in a conductive solution. A theoretical model was proposed to determine the influence of the electrode size, the interelectrode distance, the size and the position of the sphere, on the electrolyte resistance. Experimental variations of ER due to the passage of spheres and measured by using a home-made electronic device are also presented in this paper. The excellent agreement obtained between the theoretical and experimental results allows validation of both model and experimental measurements. In addition, the technique was shown to be able to perform accurate measurements of the velocity of a ball falling in a liquid.
\end{abstract}

Keywords: Particle sizing techniques; Two-phase systems; Electrochemical noise; Electrolyte resistance

* Corresponding author. Tel.: +33-1-44279617; fax: 33-1-44274074

E-mail address: kieu.ngo@upmc.fr (K. Ngo)

${ }^{1}$ ISE member 


\section{Introduction}

Many industrial processes highlight the importance of multiphase flows, in particular those involving two phases where a gaseous, liquid or solid phase is dispersed at various scales in a continuous liquid phase. Examples of such processes are encountered in a wide variety of technical applications, including inkjet printers, deposition and coating, direct injection internal-combustionengines, gas turbines, etc. The dispersed phase can lead to homogeneous or separated flows, suspensions or bubbly flows, etc. Among the two-phase systems, those with dispersed discrete particles play an important role, for example in the pharmaceutical and cosmetic industries. Hence, it is essential to seek reliable techniques to characterize the particles in mixtures because they have a direct impact on product quality [1].

The various methods for particle sizing in multiphase flows have been reviewed in [2-5]. Recently, the techniques based on optical technologies have emerged as standard tools because of their numerous advantages such as a high spatial resolution, a moderate temporal resolution, and a large range of applicability. They are widely used for dense multiphase flows in industrial processes and in microstructures as well, for example for biological cell counting and sizing [6-11]. In addition to complex and expensive equipments, the main disadvantage of these techniques is their dependence on the visibility of the measurement volume and on the focal distance. Moreover, they are difficult to adapt to hostile environments, for example at high temperature and/or high pressure.

Since particles of different size can be physically separated, non-optical techniques for particle sizing have also been developed like sieving, gravitational sedimentation, centrifuging, etc [12-14]. Sensors for particle sizing have been developed using electrostatic and acoustic techniques [15-17]. The most popular technique based on electrical measurement is the electrical sensing zone method (Electrozone Counter or Coulter Principle), in which particles are suspended in an electrolyte and forced to flow through a small orifice. The change in electrical resistivity of the solution between two electrodes placed on either side of the orifice allows the particle size to be 
determined [18-20]. This method has been applied to many applications but its main disadvantage is that particles may get trapped in the orifice and cause plugging.

During the past thirty years, the electrochemical noise (EN) technique has been developed in our laboratory to study two-phase flows using electrodes immerged in a conductive electrolyte. Indeed, the presence of discrete entities (gas bubbles, oil droplets, solid particles...) near a working electrode generates fluctuations of current, potential, and also fluctuations of the electrolyte resistance (ER) between the reference electrode and the working electrode that are provoked by changes in the current distribution (screening effects) [21-25]. The analysis of the EN signals in both time and frequency domains allows a more precise identification of the elementary events at the origin of noise, which is not possible with classical electrochemical methods, such as impedance spectroscopy or cyclic voltammetry, that give information averaged in time and over the electrode surface. This technique has been successfully applied to determine the size and departure rate of bubbles on a gas-evolving electrode [21-22], to determine the electrical charge exchanges between conductive beads and a current collector [23], to get a detailed view of the approach and residence of microcapsules close to the electrode during composite plating [24], or to characterize the composition of oil-brine mixtures in a flow-loop cell [25].

The objective of this work was to assess the possibility to use the electrochemical noise as an alternative technique for particle sizing in two-phase flows. As a preliminary step, single particles were used in this first paper. Numerical simulations were performed to study the influence on the ER of an insulating sphere passing through two electrodes immerged in a conductive electrolyte and an experimental work was carried out to validate the simulation results.

\section{Theoretical simulation}

In order to determine the influence of the presence of an insulating sphere on the ER measured between two electrodes immersed in a conductive electrolyte, a theoretical model has been developed using COMSOL Multiphysics 4.1 software. As shown in Fig. 1, two disks of 
diameter $d_{\mathrm{e}}$ represent the two electrodes positioned face-to-face. The electrolyte is contained in a cuboid of dimensions $l_{\mathrm{x}}, D, l_{\mathrm{z}}$, where $D$ is the distance between the two electrodes, and $d_{\mathrm{p}}$ is the diameter of the sphere that will descend along the z-axis in the experimental section. The $l_{\mathrm{x}}$ and $l_{\mathrm{z}}$ values are chosen large enough $(100 \mathrm{~mm})$ compared to the diameter of the electrodes and the interelectrode distance, so that they have no significant influence on the simulation results.

To calculate the ER (impedance at high frequency) an electrical model was chosen in this work instead of an electrochemical model to simplify the simulation. This model is valid as long as the concentration and the temperature of the electrolyte, and hence its conductivity, $\kappa$, are constant. A difference of potential is applied between the two electrodes and the ER is calculated from the resulting current on the electrodes. Only the primary current and potential distributions were considered in this work since kinetic and mass transport phenomena can be neglected at the high frequency, typically $100 \mathrm{kHz}$, at which the ER is measured. The potential, $\phi$, can be calculated at any point between the two electrodes using the Laplace equation:

$$
\nabla^{2} \phi=0
$$

The first integration of this equation allows the current density, $J$, to be determined:

$$
J=-\kappa \nabla \phi
$$

The following boundary conditions were applied in the simulation:

i) the normal component of the current, - n.J, was equal to 0 at any point of all the insulating surfaces of the sphere and around the electrodes, as well as on the boundaries of the cuboid.

ii) a difference of potential, $V_{\text {app }}$, of $30 \mathrm{mV}$ was applied between the two electrodes $(+30 \mathrm{mV}$ was applied to one electrode and $0 \mathrm{mV}$ to the other one that was considered to be the grounded electrode).

The value of the electrolyte conductivity, $\kappa=28 \mathrm{~S} / \mathrm{m}$ (resistivity of $3.6 \Omega \mathrm{cm}$ ), was taken as that of the electrolyte used in the experimental part presented below.

As an example, Fig. 2 presents the potential and current density distributions in the presence of an insulating sphere. To improve the accuracy of the simulation, the calculations were performed using the finite element method with a more precise mesh on the surface of both electrodes. It may 
be noted in Fig. 2b that the current lines are strongly deflected close to the electrode edges and around the sphere.

The ER measured between the two electrodes was determined from the ratio $V_{\text {app }} / I$, where $I$ is the current flowing between the electrodes. $I$ was calculated by integrating the current density on the surface of the non-grounded electrode. The variation of the ER, $\Delta R_{\mathrm{e}}$, due to the presence of the sphere is then:

$$
\Delta R_{\mathrm{e}}=R_{\mathrm{ep}}-R_{\mathrm{ea}}
$$

where $R_{\mathrm{ep}}$ and $R_{\mathrm{ea}}$ are the ER in the presence and in the absence of the sphere between the electrodes, respectively. The normalized ER variation, $\Delta R_{\mathrm{e}, \mathrm{norm}}$, defined as:

$$
\Delta R_{\mathrm{e}, \text { norm }}=\frac{\left(R_{\mathrm{ep}}-R_{\mathrm{ea}}\right)}{R_{\mathrm{ea}}} \times 100
$$

depends on 6 parameters, the position $(x, y, z)$ of the sphere centre, the sphere diameter $d_{\mathrm{p}}$, the electrode diameter $d_{\mathrm{e}}$, and the interelectrode distance $D$. The influence of these parameters on $\Delta R_{\mathrm{e}, \text { norm }}$ is presented in the following sections in order to assess the possibility to determine the sphere diameter in single-particle sizing experiments, in which $d_{\mathrm{e}}$ and $D$ are fixed parameters.

\subsection{Influence of the position of the insulating sphere}

Fig. 3 shows the $R_{\mathrm{e}}$ and $\Delta R_{\mathrm{e}}$ values for an insulating sphere of $6 \mathrm{~mm}$ in diameter positioned at several positions along the vertical $z$ axis and various $x$ positions $(y=0)$ between two electrodes of diameter $d_{\mathrm{e}}=5 \mathrm{~mm}$ and an interelectrode distance $D=20 \mathrm{~mm}$. Because of the symmetry of the problem, the variations of $R_{\mathrm{e}}$ as a function of $x$ or $\mathrm{z}$ are identical; for example, $R_{\mathrm{e}}=6.3664 \Omega$ for $\mathrm{z}=$ 0 and $x= \pm 5 \mathrm{~mm}$, and for $x=0$ and $z= \pm 5 \mathrm{~mm}$. It can be noticed that $R_{\mathrm{e}}$ starts increasing much before the sphere passes in front of the electrodes in the $z$ or $x$ direction, at a distance about three times larger than the electrode diameter, indicating that the current lines are modified on long distances by the presence of the sphere. The maximum value of $R_{\mathrm{e}}$ is obtained when the centre of the sphere is positioned exactly on the axis of the two electrodes ( $x=z=0$ ), where the screening 
effect is the most important. Consistently, the variation of $R_{\mathrm{e}}$ is symmetrical around the origin $z=0$. It must be noted that, despite a sphere diameter slightly larger than the electrode diameter, the maximum value of the ER increase due to the presence of the sphere is rather low: $\Delta R_{\mathrm{e}}=46.1 \mathrm{~m} \Omega$ at $z=0$, which gives a normalized ER increase $\Delta R_{\mathrm{e}, \mathrm{norm}}=0.73 \%$.

Fig. 4 shows the ER values when the sphere is not at the same distance of both electrodes $(y \neq 0)$. The highest values are obtained when the sphere is moved closer to one of the electrodes (Fig. 4a) because of a stronger constriction of the current lines between the sphere and the closest electrode. For this reason, the maximum value of the ER variations is obtained when the sphere is in contact with one of the electrodes $\left(\Delta R_{\mathrm{e}}=1.16 \Omega\right.$ for $y= \pm 7 \mathrm{~mm}$ and $\left.x=0\right)$. It should be noticed that when the centre of the sphere is on the axis of the disk electrodes $(x=z=0)$, the ER values are relatively close together in the middle of the channel $\left(\Delta R_{\mathrm{e}}=53 \mathrm{~m} \Omega \pm 15 \%\right.$ for $\left.|y|<2 \mathrm{~mm}\right)$, as shown in Fig. 4b. This indicates that in single-particle sizing experiments, it is important to force the particle to flow at approximately the same distance of both electrodes since in that case $\Delta R_{\mathrm{e}, \text { norm }}$ depends on $x, z$, and $d_{\mathrm{p}}$ only.

\subsection{Influence of the insulating sphere diameter $d_{\mathrm{p}}$}

The influence of the diameter of the insulating sphere on the ER increase was investigated for spheres centred at the origin $\mathrm{O}(x=y=z=0)$. The normalized ER variations, which are given in Fig.5 for three interelectrode distances, increase with the sphere diameter, the upper limit corresponding to the case where the sphere touches both electrodes $\left(\Delta R_{\mathrm{e}, \mathrm{norm}}=99 \%, 156 \%\right.$, and $179 \%$ for $D=d_{\mathrm{p}}=10,15$, and $20 \mathrm{~mm}$, respectively). The analytical dependence of $\Delta R_{\mathrm{e}, \text { norm }}$ on the sphere diameter is not trivial; two behaviours can be observed in Fig. 5, one for $d_{\mathrm{p}}<D / 2$, the other one for $d_{\mathrm{p}}>D / 2$ where the $\Delta R_{\mathrm{e}, \text { norm }}$ increase with $d_{\mathrm{p}}$ is stronger. A power law can be observed in Fig. 5 for small spheres and all three interelectrode distances:

$$
\Delta R_{\mathrm{e}, \mathrm{norm}}\left(d_{\mathrm{p}}\right)=a d_{\mathrm{p}}^{b}
$$


where $a=0.039,0.0087$, and 0.0031 for $D=10,15$, and $20 \mathrm{~mm}$, respectively, and $b=3.05 \pm 0.05$

in all 3 cases, according to the linear fitting performed on the (log $\left.d_{\mathrm{p}}, \log \Delta R_{\mathrm{e}, \mathrm{norm}}\right)$ data. In the study of the ER variation induced by a spherical bubble in contact with an infinite electrode [26] or a disk electrode $[27,28]$, a power close to 3 was already obtained for the exponent of the sphere diameter.

\subsection{Influence of the interelectrode distance $D$}

Fig. 6a shows the ER values as a function of the interelectrode distance for spheres of various diameters centred at the origin $\mathrm{O}$. Two regions may be distinguished. In Region 1, which corresponds to spheres of diameter smaller than the electrode diameter, the current lines can flow directly from one electrode to the other without being too much deviated by the presence of the insulating sphere, so that $R_{\mathrm{e}}$ increases with the interelectrode distance. In contrast, the current lines

are strongly constricted close to the electrodes for bigger spheres ( $d_{\mathrm{p}}>d_{\mathrm{e}}$, Region 2 ). As a consequence, $R_{\mathrm{e}}$ starts decreasing when $D$ increases up to a value of about $2 d_{\mathrm{p}}$, where $R_{\mathrm{e}}$ increases as for the smaller spheres.

The normalized ER increment due to the presence of the sphere is given in Fig. 6b in a loglog scale. In Region 2, as soon as $D$ is larger than $2 d_{\mathrm{p}}$, a power law can be observed:

$$
\Delta R_{\mathrm{e}, \mathrm{norm}}(D)=c D^{-d}
$$

where the exponent $d$ is very close to 4 . For the smaller spheres (Region 1), a power law may also be observed, but at values of $D$ much higher than $2 d_{\mathrm{p}}$ and with an exponent slightly lower than 4 . All fitted curves shown in Fig. 6b were obtained by a linear fitting performed on the ( $\log D$, $\log \Delta R_{\mathrm{e}, \text { norm }}$ ) data. 


\subsection{Influence of the electrode diameter $d_{e}$}

The influence of the electrode diameter on the ER is shown in Fig. 7 for a sphere of diameter $6 \mathrm{~mm}$ centred at the origin $\mathrm{O}$. As expected, the smaller the electrode, the higher the ER value because of a stronger constriction of the current lines close to the electrodes. It should be noted that the influence of the sphere is so small, according to the low $\Delta R_{\mathrm{e}, \text { norm }}$ values, that the $R_{\mathrm{e}}$ values in the absence or in the presence of the sphere would not be distinguishable in Fig. 7 . In contrast, $\Delta R_{\mathrm{e}, \text { norm }}$ increases with the electrode diameter, indicating that the passage of particles can be more easily detected when using electrodes larger than the particle.

\subsection{Method for particle sizing}

Once the electrode diameter and interelectrode distance have been chosen, the ER variation $\Delta R_{\mathrm{e}}$ induced by the passage of a single spherical particle depends on 4 parameters, the position $(x, y$, $z$ ) of the particle centre and the particle diameter $d_{\mathrm{p}}$. According to Fig. 4b, the influence of the lateral position $y$ on $\Delta R_{\mathrm{e}}$ is not significant when the particle flows close to the middle of the channel between the electrodes, so that $\Delta R_{\mathrm{e}}$ depends only on $x, z$ and $d_{\mathrm{p}}$ under this experimental condition. For a given sphere diameter, an empirical expression of $\Delta R_{\mathrm{e}}$ as a function of $\mathrm{z}$ can be determined for $x=0$ with the help of the plot of $\Delta R_{\mathrm{e}}(\mathrm{z})$ in a semi-logarithmic scale that indicates a linear $z$ dependence of $\log \left(\Delta R_{\mathrm{e}}\right)$ for high $z$ values. As shown in Fig. 8a for $D=20 \mathrm{~mm}$ and $d_{\mathrm{e}}=5 \mathrm{~mm}$, which are the values used in the experimental work, the following expression with parameters obtained by fitting the $\Delta R_{\mathrm{e}}$ values presented in Fig. $3\left(d_{\mathrm{p}}=6 \mathrm{~mm}\right)$ gives an excellent result:

$$
\Delta R_{\mathrm{e}}\left(x=0, z, d_{\mathrm{p}}=6 \mathrm{~mm}\right)=\frac{0.0668+0.0081|z|}{1+0.43851 \times 10^{0.17578|z|}} \quad(\mathrm{z} \text { in mm })
$$

Because of the symmetry of the problem, the isovalues of $\Delta R_{\mathrm{e}}$ are located on circles of equation " $x^{2}+z^{2}=$ constant" when $y=0$, so that the previous empirical expression can be directly extended to any position $(x, z)$ of the sphere centre by replacing $|z|=\sqrt{z^{2}}$ with $\sqrt{x^{2}+z^{2}}$ : 


$$
\Delta R_{\mathrm{e}}\left(x, z, d_{\mathrm{p}}=6 \mathrm{~mm}\right)=\frac{0.0668+0.0081 \sqrt{x^{2}+z^{2}}}{1+0.43851 \times 10^{0.17578 \sqrt{x^{2}+z^{2}}}} \quad(x, z \text { in mm })
$$

which is confirmed by the excellent agreement in Fig. 8a between the $\Delta R_{\mathrm{e}}$ values for $\mathrm{x} \neq 0$ and the solid red lines obeying Eq. 8.

Finally, to derive an expression of $\Delta R_{\mathrm{e}}$ including the dependency on $d_{\mathrm{p}}$, the power law identified in Eq. 5 for $d_{\mathrm{e}}<D / 2$ was used despite the fact it was obtained for a sphere centred at the origin O. Fig.8b shows an excellent agreement between the $\Delta R_{\mathrm{e}}$ values calculated for $d_{\mathrm{p}}=3 \mathrm{~mm}$ at different $x$ and $z$ values and the solid red lines obeying the following expression with a value of 3.05 for the exponent of $d_{\mathrm{p}}$.

$$
\Delta R_{\mathrm{e}}\left(x, z, d_{\mathrm{p}}\right)=\frac{0.0668+0.0081 \sqrt{x^{2}+z^{2}}}{1+0.43851 \times 10^{0.17578 \sqrt{x^{2}+z^{2}}}}\left(\frac{d_{\mathrm{p}}}{6}\right)^{3.05} \quad\left(x, z, d_{\mathrm{p}} \text { in mm }\right)
$$

In single-particle sizing experiments, the diameter $d_{\mathrm{p}}$ of the sphere must be determined from the experimental transient $\Delta R_{\mathrm{e}}(\mathrm{z})$ such as those presented below when the sphere flows vertically in the channel. Still assuming that $y$ is close to 0 , the amplitude $\Delta R_{\mathrm{e}, \max }$ of the transient at $z=0$, which can be easily determined, depends on $x$ and $d_{\mathrm{p}}$. While a fitting procedure using Eq. 9 could give both $x$ and $d_{\mathrm{p}}$ values, an easier way consists in considering experiments in which the particle flows at a distance $x$ close to 0 . Indeed, the influence of $x$ on $\Delta R_{\mathrm{e}, \max }$ is relatively low in that case (for $|x|$ $<2 \mathrm{~mm}, \Delta R_{\mathrm{e}, \max }=43.9 \mathrm{~m} \Omega \pm 5 \%$ for $d_{\mathrm{p}}=6 \mathrm{~mm}$ and $5.4 \mathrm{~m} \Omega \pm 5 \%$ for $\left.d_{\mathrm{p}}=3 \mathrm{~mm}\right)$. As a consequence, the diameter $d_{\mathrm{p}}$ can be evaluated with the following expression derived from Eq. 9 with $x=z=0$. This expression will be used below in the experimental part.

$$
d_{\mathrm{p}}=16.42\left(\Delta R_{\mathrm{e}, \max }\right)^{0.328} \quad\left(\Delta R_{\mathrm{e}, \max } \text { in } \Omega, d_{\mathrm{p}} \text { in mm }\right)
$$

\section{Experimental}

All experiments were performed at room temperature in a large glass crystallizing dish of 17 $\mathrm{cm}$ in diameter and $10 \mathrm{~cm}$ in height. The two working electrodes were the cross-section of platinum 
rods of $5 \mathrm{~mm}$ in diameter embedded in epoxy resin and mounted flush in two parallel planes of a Teflon holder located at the dish centre. The distance between the two electrodes positioned face to face was $20 \mathrm{~mm}$. The electrolyte was a $0.7 \mathrm{M} \mathrm{H}_{2} \mathrm{SO}_{4}$ solution prepared with deionised water. Its conductivity, which depends on the room temperature, was measured before each experiment with a conductivity meter (Meterlab CDM230) and adjusted to the value of $28 \mathrm{~S} / \mathrm{m}$ by adding a few droplets of sulfuric acid or water. Nevertheless, the room temperature could change a little bit when performing long experiments, which had an effect on the amplitude $\Delta R_{\mathrm{e}}$ of the experimental transients and on the mean value of the ER measured in the absence of sphere. However, this effect was not significant on the derived value of $\Delta R_{\mathrm{e}, \text { norm }}$.

Alumina spheres of various diameters, 3, 5, 6, 8, and $10 \mathrm{~mm}$ of excellent sphericity (tolerance $\pm 2.5 \mu \mathrm{m}$ in diameter) from Goodfellow were used as insulating spheres. To ensure that the insulating sphere could fall the most exactly possible at a given position between the two electrodes, a specific Teflon funnel with a narrow stem of diameter slightly larger than that of the sphere was used for each sphere to guide it. Moreover, the lower part of the stem was immerged in the solution to avoid any disturbance of the sphere trajectory when contacting the electrolyte.

The ER fluctuations were measured using the home-made electronic device shown in Fig. 9 [24]. The two electrodes were polarized at the same potential using a home-made potentiostat applying a $0 \mathrm{mV}$ potential difference between the two electrodes, one acting as the working electrode, the other as counter electrode. No reference electrode was used. A sinusoidal voltage signal, $v_{\mathrm{hf}}$, of peak-to-peak amplitude about $50 \mathrm{mV}$ and high frequency $f_{\mathrm{hf}}=100 \mathrm{kHz}$ was applied between the two electrodes to measure the ER. Indeed, at this high frequency, the effect of the double layer is eliminated and only the ER has to be considered in the electrochemical impedance. The sine wave current response, $v_{\mathrm{hf}} / R_{\mathrm{e}}$, measured across the resistor $R$, was passed through a capacitor to remove any residual DC offset, amplified and high-pass filtered at $20 \mathrm{kHz}$ to eliminate low-frequency current fluctuations. The signal was then rectified with a diode and low-pass filtered at $10 \mathrm{kHz}$, so that the amplitude of the voltage output signal, $v_{R_{\mathrm{e}}}$, obeyed the following relationship: 


$$
v_{R_{\mathrm{e}}}=b \frac{1}{R_{\mathrm{e}}}+d
$$

The parameters $b$ and $d$ were determined through a calibration procedure in which the electrochemical cell was replaced by pure resistors. From Eq. 11, the mean value of the ER, $R_{\mathrm{e}}$, could be calculated from the mean value of $v_{R_{\mathrm{e}}}$ measured during the electrochemical experiments. After DC-offset elimination, amplification (gain $G_{3}=-10$ ), and analog low-pass filtering to prevent aliasing, the variations of $v_{R_{\mathrm{e}}}$ due to the passage of spheres were acquired with a real-time data acquisition system (Concurrent Computer, Maxion 9100) at different sampling frequencies. The variations of the ER, $\Delta R_{\mathrm{e}}$, could be derived from the measured variations $\Delta v_{R_{\mathrm{e}}}$ with the equation:

$$
\Delta R_{\mathrm{e}}=-\frac{R_{\mathrm{e}}^{2}}{b G_{3}} \Delta v_{R_{\mathrm{e}}}
$$

obtained by differentiating Eq. 11 for $R_{\mathrm{e}}$ variations of small amplitude. Experimental results and comparison with theory are presented in the next section for insulating spheres of various diameters falling between the two electrodes at a position $x$ and $y$ close to 0 .

\section{Results and discussion}

Fig. 10 shows three typical examples of the variations of the output voltage signal $v_{R_{\mathrm{e}}}$ due to the passage of insulating spheres of diameters $10 \mathrm{~mm}, 6 \mathrm{~mm}$, and $3 \mathrm{~mm}$ between the electrodes. The sampling frequency was $20 \mathrm{kHz}$ in the first two cases and $1 \mathrm{kHz}$ in the latter case. It is important to note the strong influence of the sphere diameter on the amplitude of the transient. For the 3-mm spheres, the amplitude of the $v_{R_{\mathrm{e}}}$ signal was much lower and it was necessary to reduce the influence of the background noise by decreasing the cut-off frequency of the low-pass anti-aliasing filter. Moreover, to still decrease the amplitude of the background noise, which was essentially due to the mains interference (50 Hz and harmonics), a digital low-pass filtering at a cut-off frequency

of $40 \mathrm{~Hz}$ was applied to the measured $v_{R_{\mathrm{e}}}$ data. The result is the red curve shown in Fig. 10. The 
corresponding $\Delta R_{\mathrm{e}}$ variations calculated with Eq. 12 and the experimental values of $R_{\mathrm{e}}$ and $b$ are presented in Fig. 11 (black curves). Moreover, this figure shows the theoretical curves (in red) fitted with Eq. 9 by replacing z with $v\left(t_{0}-t\right)$, where $v$ is the velocity of the sphere and $t_{0}$ the time instant at which the sphere passes at the vertical position $z=0$. The agreement is so good between the experimental and theoretical curves that it is hardly possible to distinguish them for the spheres of $10 \mathrm{~mm}$ and $6 \mathrm{~mm}$ in diameter. The adjusted parameters $x, v, t_{0}$, and $d_{\mathrm{p}}$ are given in Table 1 , together with characteristic parameters of the hydrodynamic flow.

As expected from the experimental procedure, the $x$ values are close to 0 . On the other hand, considering that the starting point of the sphere fall was far enough of the electrodes, the sphere velocity could be assumed to be constant in front of the electrodes. This was confirmed by the perfect symmetry of the $v_{R_{\mathrm{e}}}$ transients. Moreover, according to Table 1 , the sphere velocity is approximately proportional to the square root of the sphere radius. This results from the fact that the drag force of the falling sphere is quadratic with velocity at high Reynolds numbers $\left(R e>10^{3}\right)$ [30]. Table 1 actually shows high values of the Reynolds number calculated according to the equation:

$$
R e=\frac{\rho_{\mathrm{e}} d_{\mathrm{p}} v}{\eta}
$$

where $\rho_{e}$ and $\eta$ are the density and dynamic viscosity of the electrolyte, respectively $\left(\rho_{e}=1.04\right.$ $\mathrm{g} \mathrm{cm}^{-3}$ and $\eta=1.0 \mathrm{~g} \mathrm{~m}^{-1} \mathrm{~s}^{-1}$ ). Table 1 also shows the terminal velocity of the falling ball, $v_{\text {ter }}$, calculated as follows:

$$
v_{\text {ter }}=\sqrt{\frac{4 g d_{\mathrm{p}}}{3 C_{\mathrm{d}}}\left(\frac{\rho_{\mathrm{e}}}{\rho}-1\right)}
$$

where $g$ is the acceleration of free fall $\left(g=9.81 \mathrm{~m} \mathrm{~s}^{-2}\right), \rho$ is the density of the falling sphere $(\rho=$ $3.95 \mathrm{~g} \mathrm{~cm}^{-3}$ ), and $C_{\mathrm{d}}$ is the drag coefficient, which depends on the Reynolds number according to the relation:

$$
C_{\mathrm{d}} \approx \frac{24}{\operatorname{Re}}+\frac{6}{1+\sqrt{R e}}+0.4
$$


The terminal velocities of these not-so-small spheres (compared to the interelectrode distance) have been calculated as if they were in an unbounded fluid. The wall-proximity effects in the near-wall region were not handled, so the drag coefficient was probably underestimated, which could explain why the terminal velocities had values larger than those of the measured velocities (by a factor of about 25\%).

The estimated values of the sphere diameter, $d_{\mathrm{p}}$, in Table 1 are in good agreement with the actual diameter of the spheres, within an error lower than 5\%, considering the fact that the position of the sphere in the $x$ and $y$ direction was not perfectly controlled during its fall. A non-zero $x$ value leads to a lower $\Delta R_{\mathrm{e}}$ value (Fig. 3) while, in contrast, a non-zero $y$ value leads to a higher value. According to the simulations, a $y$ value of about $\pm 1 \mathrm{~mm}$ explains the overestimated diameter of $10.488 \mathrm{~mm}$ for the $10 \mathrm{~mm}$-diameter sphere. The straightforward Eq. 10 gives the same values for the diameter of the spheres.

Fig. 11 shows that it would be difficult to characterize spheres of diameter much smaller than $3 \mathrm{~mm}$ with the present experimental set-up $\left(D=20 \mathrm{~mm}, d_{\mathrm{e}}=5 \mathrm{~mm}\right)$ without improving the measurement of the ER variations by decreasing its background noise. Another solution consists in using closer electrodes as, for example, in microreactors. This will be presented in a future paper.

Additional experiments were performed with spheres of various sizes. In order to insure the reproducibility of the results, at least six experiments were carried out for each sphere diameter. From the $v_{R_{\mathrm{e}}}$ transients measured due to the passage of the insulating spheres on the vertical line $x=y=0$, the maximum amplitude, $\Delta R_{\mathrm{e}, \max }$, of the $\Delta R_{\mathrm{e}}$ transients was estimated. The standard

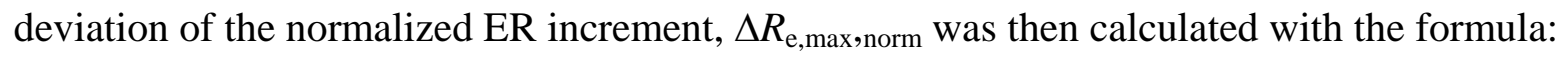

$$
\sigma=\sqrt{\frac{1}{n-1} \sum_{n}\left(\Delta R_{\mathrm{e}, \text { max }, \text { norm }}-\overline{\Delta R_{\mathrm{e}, \text { max }, \text { norm }}}\right)^{2}}
$$

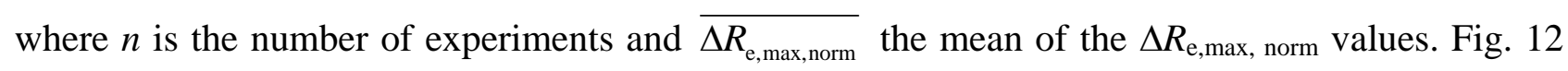
shows the theoretical and experimental $\Delta R_{\mathrm{e}, \text { norm }}$ values as a function of the sphere diameter. It must noticed that the experimental errors are close (about 4-5\%) for all sphere diameters, which means 
that the error was not due to the accuracy of the ER measurements, since otherwise it would be more important for the small spheres. This error comes from the fact that the spheres did not always fall exactly on the vertical line $x=y=0$ between the two electrodes. All experimental $\Delta R_{\mathrm{e}, \max , \text { norm }}$ values are in close agreement with the theoretical values, as shown in Fig. 12.

\section{Conclusions}

This paper investigates the influence of an insulating sphere on the electrolyte resistance between two electrodes immerged in an electrolytic solution, to assess the method as a singleparticle sizing technique at millimeter scale. A theoretical model using the finite element method was developed to study the influence of different parameters such as the size and the position of the sphere, the diameter of the electrodes and the interelectrode distance. Experiments were performed with different insulating spheres using a home-made electronic device. The excellent agreement between the experimental and theoretical results allows validation of both the theoretical model and the experimental setup able to measure fast electrolyte resistance variations in the millisecond range. For the moment, the technique allows particle sizing for spheres of diameter larger than onetenth of the interelectrode distance. Improvement may be obtained by reducing the background noise of the ER measurement. Apart from particle sizing, this specific electrochemical noise technique is able to perform accurate measurements of the sphere velocity without the help of optical techniques, which could be interesting in some applications as for viscosity measurements with falling balls. Only results with insulating spheres have been shown in this paper but the technique also works well with metallic spheres as long as there is a significant difference between the liquid and sphere conductivities. The development of a microfluidic platform is in progress in our laboratory to extend this technique to the micrometer scale and analyze smaller particles. 


\section{References}

[1] C. Kleinstreuer, Two-Phase Flow: Theory and Applications, Taylor \& Francis Books, Inc, New York, 2003.

[2] N.E. Tayali, C.J. Bates, Particle sizing techniques in multiphase flows: A review, Flow Meas. Instrum. 1 (1990) 77-105.

[3] M. Bieberle, F. Fisher, E. Schleicher, D. Koch, H.-J. Menz, H.-G. Mayer, U. Hampel, Experimental two-phase flow measurement using ultra fast limited-angle-type electron beam X-ray computed tomography, Exp. Fluids 47 (2009) 369-378.

[4] R. Xu, O.A. Di Guida, Comparison of sizing small particles using different technologies, Powder Technol. 132 (2003) 145-153.

[5] W.L. Snowsill, Particle Sizing, in: Instrumentation Reference Book, 2010, pp. 175-189.

[6] G. Gouesbet, G. Gréhan, Laser-based optical measurement techniques of discrete particles: A review, Int. J. of Multiphas. Flow 72 (2015) 288-297.

[7] M. Honkanen, H. Eloranta, P. Saarenrinne, Digital imaging measurement of dense multiphase flows in industrial processes, Flow Meas. Instrum. 21 (2010) 25-32.

[8] A.F.T. Silva, A. Burggraeve, Q. Denon, P. Van der Meeren, N. Sandler, T. Van Den Kerkhof, M. Hellings, C. Vervaet, J.P. Remon, J.A. Lopes, T. De Beer, Particle sizing measurements in pharmaceutical applications: comparison of in-process methods versus offline methods, Eur. J. Pharm. Biopharm. 85 (2013) 1006-1018.

[9] P. Telleman and U.D. Larsen, Cell counting and cell sizing in microstructures, in: Lab-on-aChip, Miniaturized Systems for (Bio)Chemical Analysis and Synthesis, R.E. Oosterbroek and A. van den Berg (Eds.), Elsevier, 2003, pp. 215-227.

[10] S.J. Satinover, J.D. Dove, M.A. Borden, Single-particle optical sizing of microbubbles, Ultrasound Med. Biol. 40 (2014) 138-147. 
[11] Z. Ma, H.G. Merkus, J.G.A.E. de Smet, C. Heffels, B. Scarlett, New developments in particle characterization by laser diffraction: size and shape, Powder Technol. 111 (2000) $66-78$.

[12] T. Allen, Particle size analysis by sieving, in: Powder Sampling and Particle Size Determination, Elsevier, 2003, pp. 208-250.

[13] C.M. Alexander, J.C. Dabrowiak, J. Goodisman, Gravitational sedimentation of gold nanoparticles, J. Colloid Interf. Sci. 396 (2013) 53-62.

[14] A. Neumann, W. Hoyer, M.W. Wolff, U. Reichl, A. Pfitzner, B. Roth, New method for density determination of nanoparticles using a CPS disc centrifuge, Colloid Surface B 104 (2013) 27-31.

[15] A. Bastari, C. Cristalli, R. Morlacchi, E. Pomponi, Acoustic emissions for particle sizing of powders through signal processing techniques, Mech. Syst. Signal Pr. 25 (2011) 901-916.

[16] F. Alba, G.M. Crawley, J. Fatkin, D.M.J. Higgs, P.G. Kippax, Acoustic spectroscopy as a technique for the particle sizing of high concentration colloids, emulsions and suspensions, Colloid Surface A 153 (1999) 495-502.

[17] T. Tajdari, M.F. Rahmat, N.A. Wahab, New technique to measure particle size using electrostatic sensor, J. Electrostat. 72 (2014) 120-128.

[18] J. Hurley, Sizing particles with a Coulter counter, Biophys. J. 10 (1970) 74-79.

[19] R. Rodriguez-Trujillo, M.A. Ajine, A. Orzan, M.D. Mar, F. Larsen, C.H. Clausen, W.E. Svendsen, Label-free protein detection using a microfluidic Coulter-counter device, Sensor. Actuat. B 190 (2014) 922-927.

[20] J.H. Nieuwenhuis, F. Kohl, J. Bastemeijer, P.M. Sarro, M.J. Vellekoop, Integrated Coulter counter based on 2-dimensional liquid aperture control, Sensor. Actuat. B 102 (2004) 4450. 
[21] C. Gabrielli, F. Huet, M. Keddam, Characterization of electrolytic bubble evolution by spectral analysis. Application to a corroding electrode, J. Appl. Electrochem. 15 (1985) 503-508.

[22] C. Gabrielli, F. Huet, M. Keddam, A. Sahar, Investigation of water electrolysis by spectral analysis, I. Influence of the current density, J. Appl. Electrochem. 19 (1989) 683-696.

[23] C. Gabrielli, F. Huet, R. Wiart, J. Zoppas-Ferreira, Dynamic behaviour of an electrolyser with a two phase solid-liquid electrolyte. Part II: Investigation of elementary phenomena and electrode modelling, J. Appl. Electrochem. 24 (1994) 1235-1243.

[24] V. Bouet, J. Fransaer, F. Huet, G. Maurin, J.P. Celis, Electrochemical resistance noise during composite plating, J. Electrochem. Soc. 145 (1998) 436-446.

[25] H. Bouazaze, F. Huet, R.P. Nogueira, Measurement of electrolyte resistance fluctuations generated by oil-brine mixtures in a flow-loop cell, Corrosion 63 (2007) 307-317.

[26] P.J. Sides, C.W. Tobias, Primary potential and current distribution around a bubble on an electrode, J. Electrochem. Soc. 127 (1980) 288-291.

[27] J. Fransaer, J.P. Celis, J.R. Roos, Variations in the flow of current to disk electrodes caused by particles, J. Electroanal. Chem. 391 (1995) 11-28.

[28] H. Bouazaze, J. Fransaer, F. Huet, P. Rousseau, V. Vivier, Electrolyte-resistance change due to an insulating sphere in contact with a disk electrode, Electrochim. Acta 55 (2010) 16451655.

[29] C. Gabrielli, F. Huet, M. Keddam, Real-time measurement of electrolyte resistance fluctuations, J. Electrochem. Soc. 138 (1991), L82-L84.

[30] J.P. Owen, W.S. Ryu, The effects of linear and quadratic drag on falling spheres: an undergraduate laboratory, Eur. J. Phys. 26 (2005) 1085-1091.

[31] F.M. White, Viscous Fluid Flow, $2^{\text {nd }}$ edition, Mc Graw-Hill, New York, 1991, p.182. 


\section{Figure and Table Captions}

Table 1 Parameters obtained by fitting the experimental curves in Fig. 11 with Eq. 9 and parameters of the hydrodynamic flow.

Fig. 1. Geometry of the model (a) and example of meshing (b). D: interelectrode distance, $d_{\mathrm{p}}$ : diameter of the insulating sphere, $d_{\mathrm{e}}$ : diameter of the disk electrodes, $l_{\mathrm{x}}, D, l_{\mathrm{z}}$ dimensions of the electrolyte volume.

Fig. 2. Distribution of potential (a) and current (b) lines in the $y$-z plane $(x=0)$ in the presence of an insulating sphere (dark circle) between the two electrodes.

Fig. 3. Variations of $R_{\mathrm{e}}$ and $\Delta R_{\mathrm{e}}$ as a function of the position of the centre of the insulating sphere along the vertical $\mathrm{Oz}$ axis for $y=0$ and different $x$ values $\left(d_{\mathrm{e}}=5 \mathrm{~mm}, D=20 \mathrm{~mm}, d_{\mathrm{p}}=\right.$ $6 \mathrm{~mm})$.

Fig. 4. Variations of $R_{\mathrm{e}}$ and $\Delta R_{\mathrm{e}}$ as a function of the position of the centre of the insulating sphere along the vertical $\mathrm{Oz}$ axis for different $y$ values (a), and along the $y$ axis for $z=0$ (b) $\left(x=0, d_{\mathrm{e}}=5 \mathrm{~mm}, D=20 \mathrm{~mm}, d_{\mathrm{p}}=6 \mathrm{~mm}\right)$.

Fig. 5. Normalized ER increment $\Delta R_{\mathrm{e}, \text { norm }}$ due to the presence of an insulating sphere of diameter $d_{\mathrm{p}}$ centred at $x=y=z=0$ for 3 interelectrode distances $D=10 \mathrm{~mm}, 15 \mathrm{~mm}$, and $20 \mathrm{~mm}$ ( $d_{\mathrm{e}}=5 \mathrm{~mm}$ ). In red, fitted curves when $d_{\mathrm{p}}$ is lower than $D / 2$.

Fig. 6. Variations of $R_{\mathrm{e}}$ (a) and $\Delta R_{\mathrm{e}, \text { norm }}$ (b) as a function of the interelectrode distance for insulating spheres of diameter $d_{\mathrm{p}}$ centred at $x=y=z=0\left(d_{\mathrm{e}}=5 \mathrm{~mm}\right)$. In red, fitted curves when $d_{\mathrm{p}}$ is lower than $D / 2$. Values of $D$ and $d_{\mathrm{p}}$ in $\mathrm{mm}$.

Fig. 7. Variations of $R_{\mathrm{e}}$ and $\Delta R_{\mathrm{e}, \text { norm }}$ as a function of the electrode diameter for an insulating sphere of diameter $d_{\mathrm{p}}=6 \mathrm{~mm}$ centred at $x=y=z=0(\mathrm{D}=20 \mathrm{~mm})$.

Fig. 8. Values of $\Delta R_{\mathrm{e}}$ as a function of the position of the centre of the insulating sphere along the vertical $\mathrm{Oz}$ axis for $y=0$ and different $x$ values $\left(d_{\mathrm{e}}=5 \mathrm{~mm}, D=20 \mathrm{~mm}\right)$ : (a) $d_{\mathrm{p}}=6 \mathrm{~mm}$, solid red lines obey Eq. 8, (b) $d_{\mathrm{p}}=3 \mathrm{~mm}$, solid red lines obey Eq. 9 . 
Fig. 9. Experimental setup used for measuring the electrolyte resistance fluctuations due to the passage of insulating spheres between two immerged electrodes.

Fig. 10. $v_{R_{\mathrm{e}}}$ variations due to the passage of single insulating spheres of diameter $10 \mathrm{~mm}, 6 \mathrm{~mm}$, and $3 \mathrm{~mm}$ between the electrodes $\left(d_{\mathrm{e}}=5 \mathrm{~mm}, D=20 \mathrm{~mm}\right)$.

Fig. 11. Experimental (black) $\Delta R_{\mathrm{e}}$ variations corresponding to the $v_{R_{\mathrm{e}}}$ variations shown in Fig. 10 as a function of the sphere position along the $z$ axis. Theoretical curves (red) calculated with Eq. 11 and fitted parameters given in Table 1.

Fig. 12. Experimental and theoretical and values of $\Delta R_{\mathrm{e}, \max \text {,norm }}$ as a function of the diameter of the insulating sphere centred at $x=y=z=0\left(d_{\mathrm{e}}=5 \mathrm{~mm}, D=20 \mathrm{~mm}\right)$. Error bars indicate twice the standard deviation of 6 sample measurements. 
Table 1

Parameters obtained by fitting the experimental curves in Fig. 11 with Eq. 9 and parameters of the hydrodynamic flow.

\begin{tabular}{lccc}
\hline Sphere diameter $(\mathrm{mm})$ & 10 & 6 & 3 \\
\hline$x(\mathrm{~mm})$ & 0.0867 & 0.142 & 0.126 \\
$t_{0}(\mathrm{~s})$ & 3.9738 & 2.7014 & 27.799 \\
$v\left(\mathrm{~mm} \mathrm{~s}^{-1}\right)$ & 632.66 & 520.53 & 324.37 \\
$d_{\mathrm{p}}(\mathrm{mm})$ & 10.488 & 6.033 & 3.128 \\
\hline$v / \sqrt{\text { sphere radius }}\left(\mathrm{mm}^{1 / 2} \mathrm{~s}^{-1}\right)$ & 282.9 & 300.5 & 264.8 \\
Reynolds number, Eq. 13 & 6580 & 3250 & 1010 \\
$C_{\mathrm{d}}$, Eq. 15 & 0.477 & 0.511 & 0.607 \\
$v_{\text {ter }}\left(\mathrm{mm} \mathrm{s}^{-1}\right)$, Eq. 14 & 876 & 656 & 425 \\
\hline
\end{tabular}


(a)

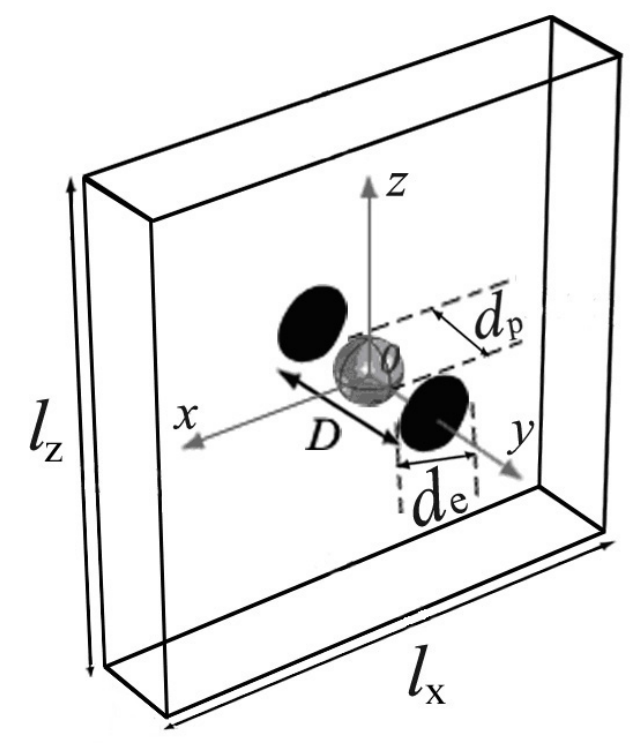

(b)

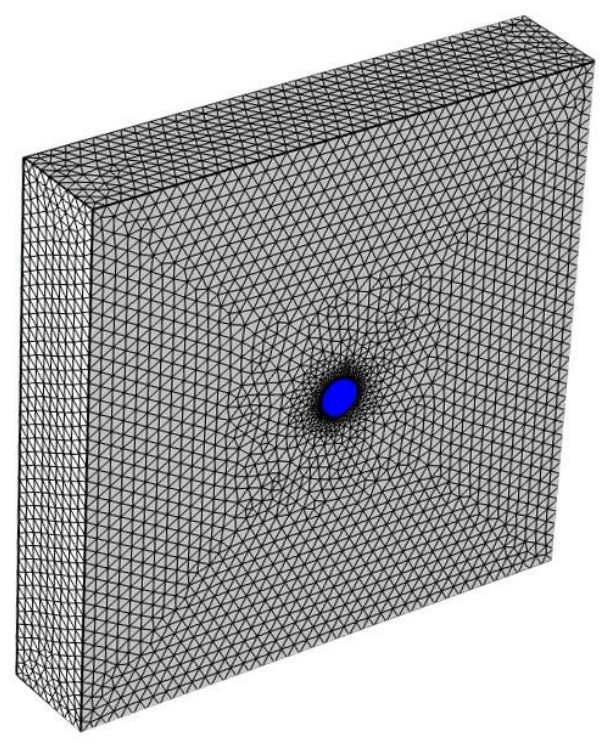

Fig. 1. Geometry of the model (a) and example of meshing (b). D: interelectrode distance, $d_{\mathrm{p}}$ : diameter of the insulating sphere, $d_{\mathrm{e}}$ : diameter of the disk electrodes, $l_{\mathrm{x}}, D, l_{\mathrm{z}}$ dimensions of the electrolyte volume. 
(a)

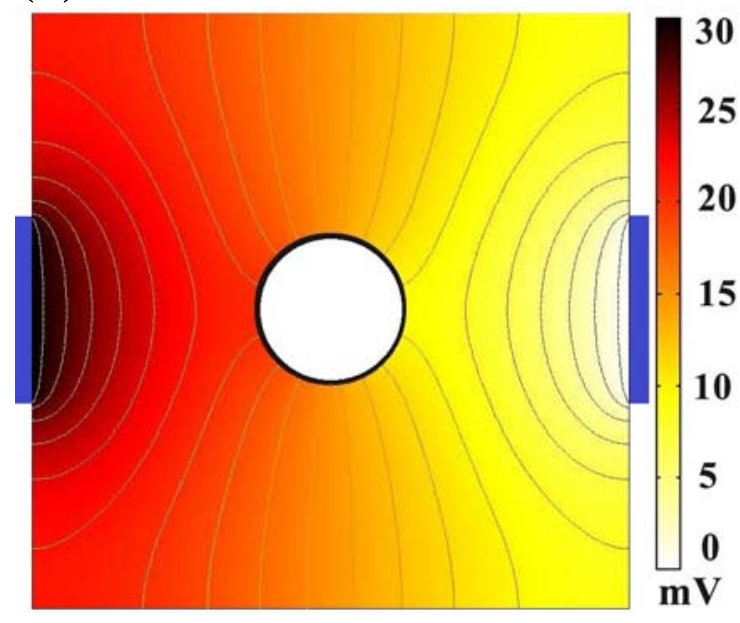

(b)

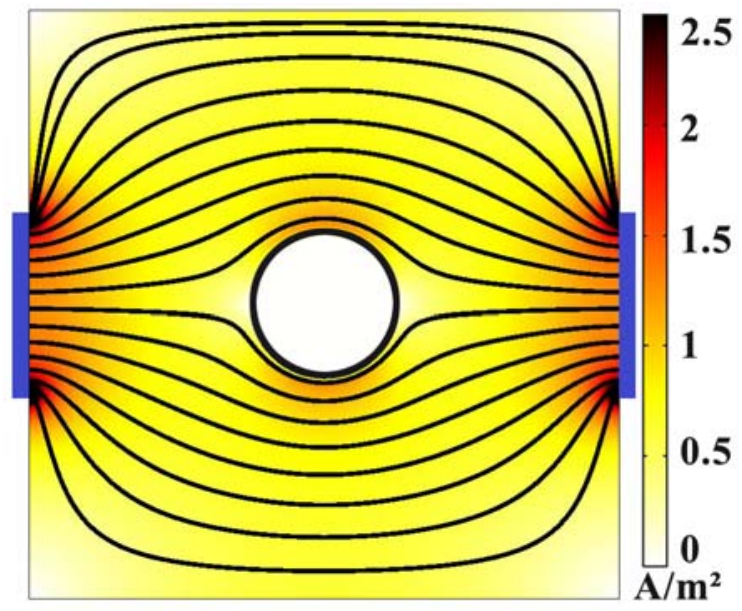

Fig. 2. Distribution of potential (a) and current (b) lines in the $y$-z plane $(x=0)$ in the presence of an insulating sphere (dark circle) between the two electrodes. 


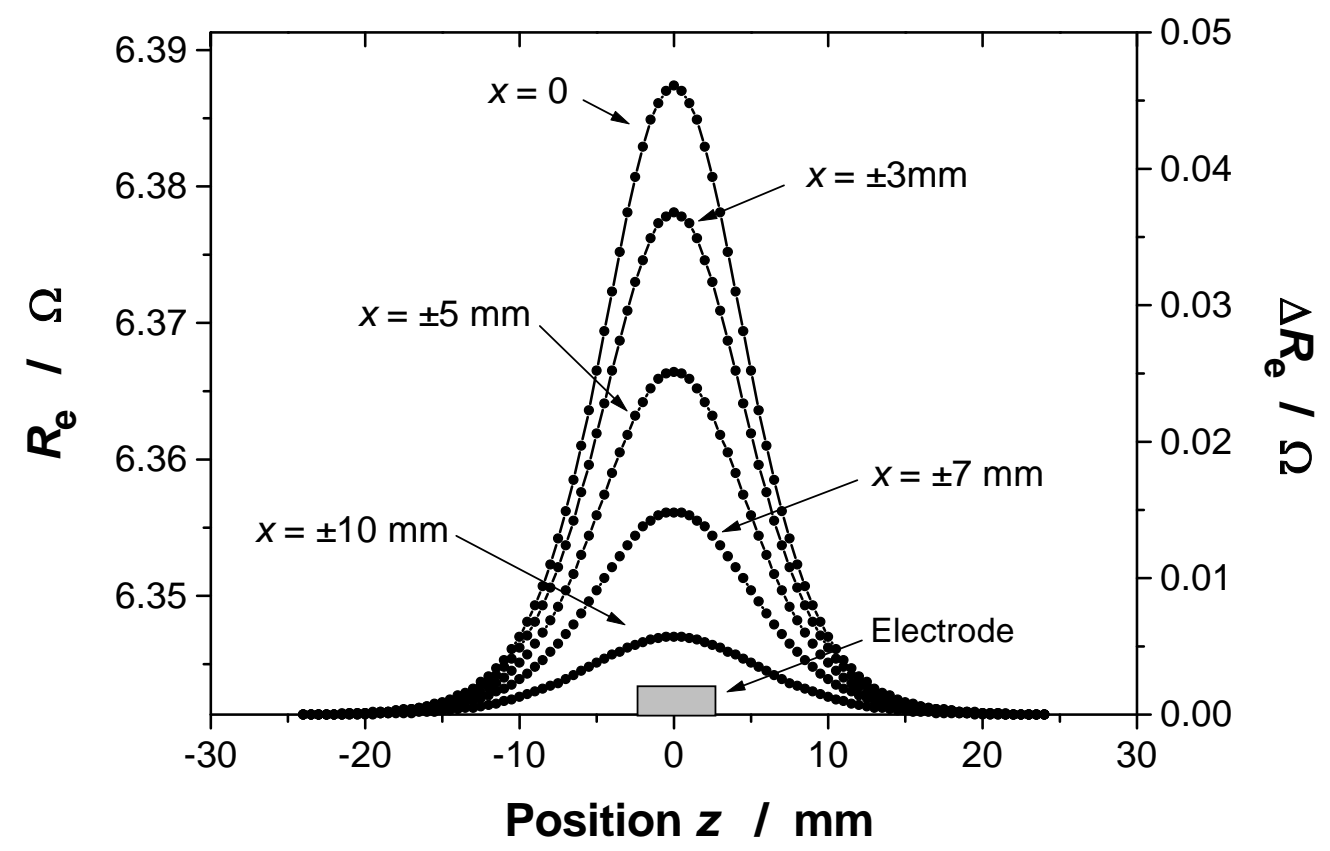

Fig. 3. Variations of $R_{\mathrm{e}}$ and $\Delta R_{\mathrm{e}}$ as a function of the position of the centre of the insulating sphere along the vertical $\mathrm{Oz}$ axis for $y=0$ and different $x$ values $\left(d_{\mathrm{e}}=5 \mathrm{~mm}, D=20 \mathrm{~mm}, d_{\mathrm{p}}=6\right.$ $\mathrm{mm})$. 

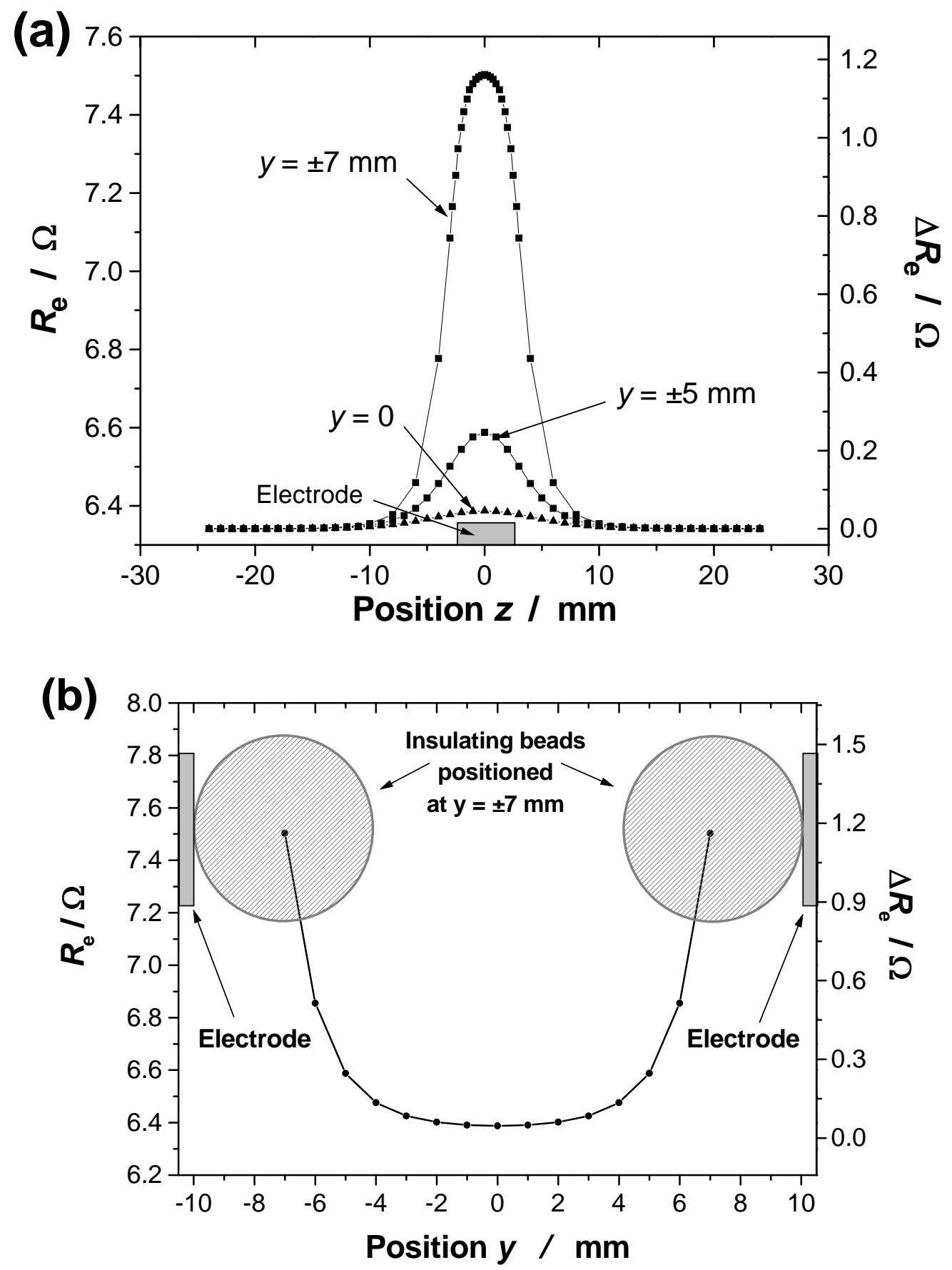

Fig. 4. Variations of $R_{\mathrm{e}}$ and $\Delta R_{\mathrm{e}}$ as a function of the position of the centre of the insulating sphere along the vertical $\mathrm{Oz}$ axis for different $y$ values (a), and along the $y$ axis for $z=0$ (b) $\left(x=0, d_{\mathrm{e}}=5 \mathrm{~mm}, D=20 \mathrm{~mm}, d_{\mathrm{p}}=6 \mathrm{~mm}\right)$. 


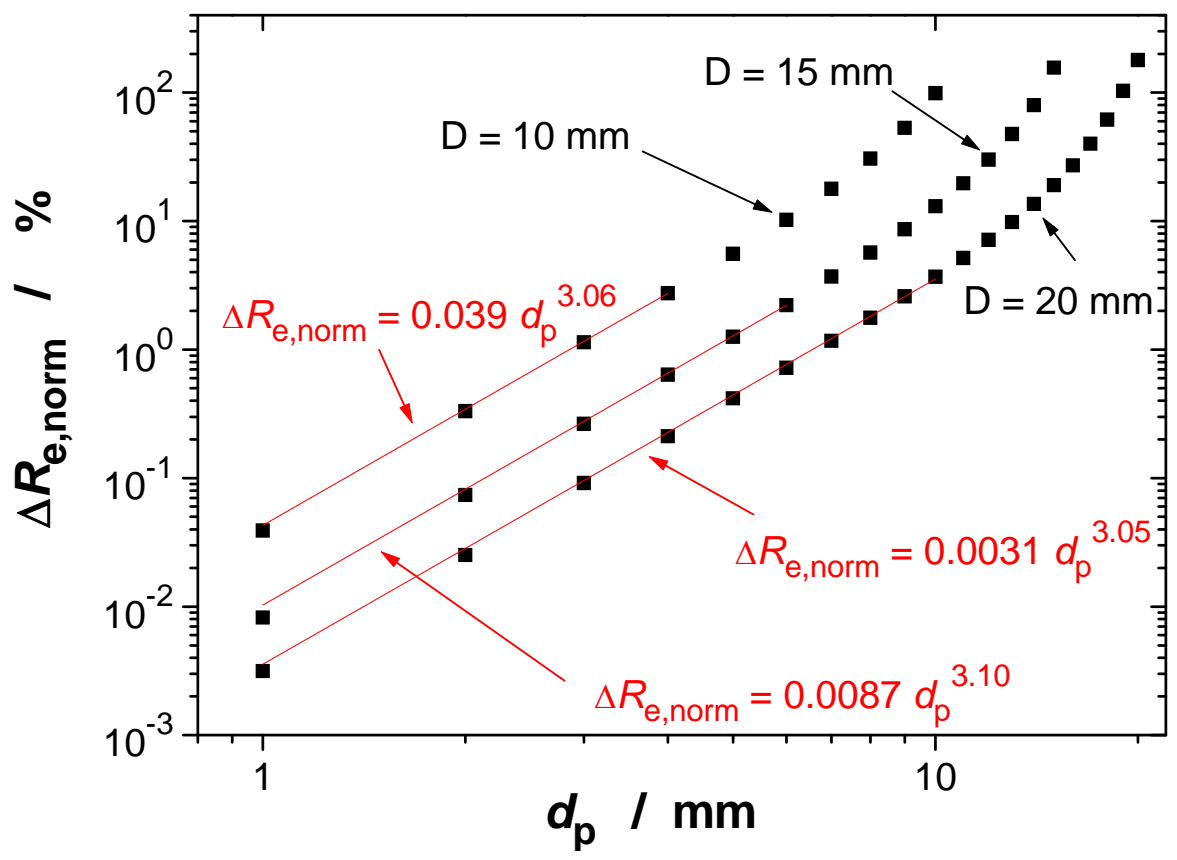

Fig. 5. Normalized ER increment $\Delta R_{\mathrm{e}, \text { norm }}$ due to the presence of an insulating sphere of diameter $d_{\mathrm{p}}$ centred at $x=y=z=0$ for 3 interelectrode distances $D=10 \mathrm{~mm}, 15 \mathrm{~mm}$, and $20 \mathrm{~mm}$ ( $\left.d_{\mathrm{e}}=5 \mathrm{~mm}\right)$. In red, fitted curves when $d_{\mathrm{p}}$ is lower than $D / 2$. 

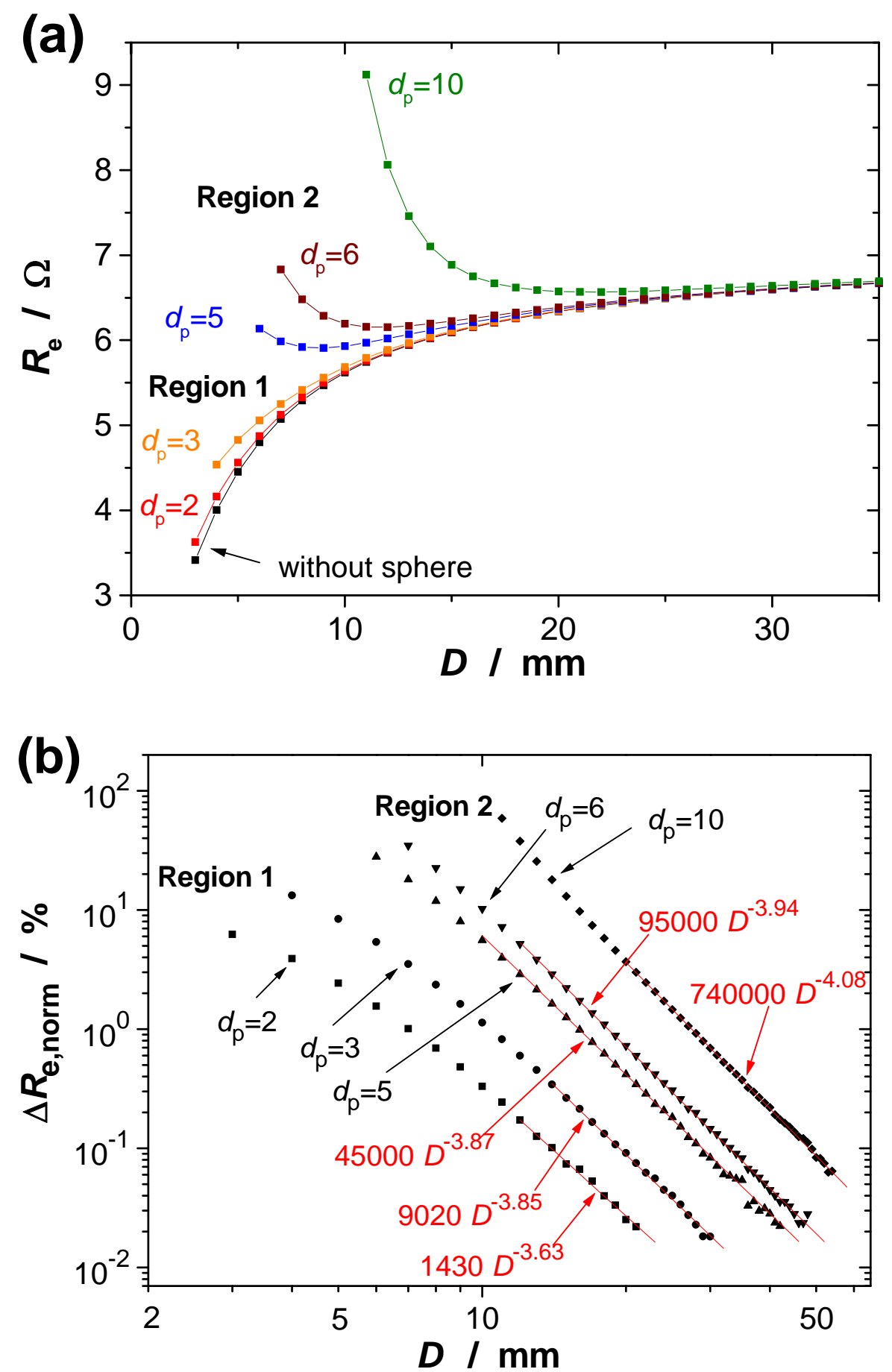

Fig. 6. Variations of $R_{\mathrm{e}}$ (a) and $\Delta R_{\mathrm{e}, \text { norm }}$ (b) as a function of the interelectrode distance for insulating spheres of diameter $d_{\mathrm{p}}$ centred at $x=y=z=0\left(d_{\mathrm{e}}=5 \mathrm{~mm}\right)$. In red, fitted curves when $d_{\mathrm{p}}$ is lower than $D / 2$. Values of $D$ and $d_{\mathrm{p}}$ in $\mathrm{mm}$. 


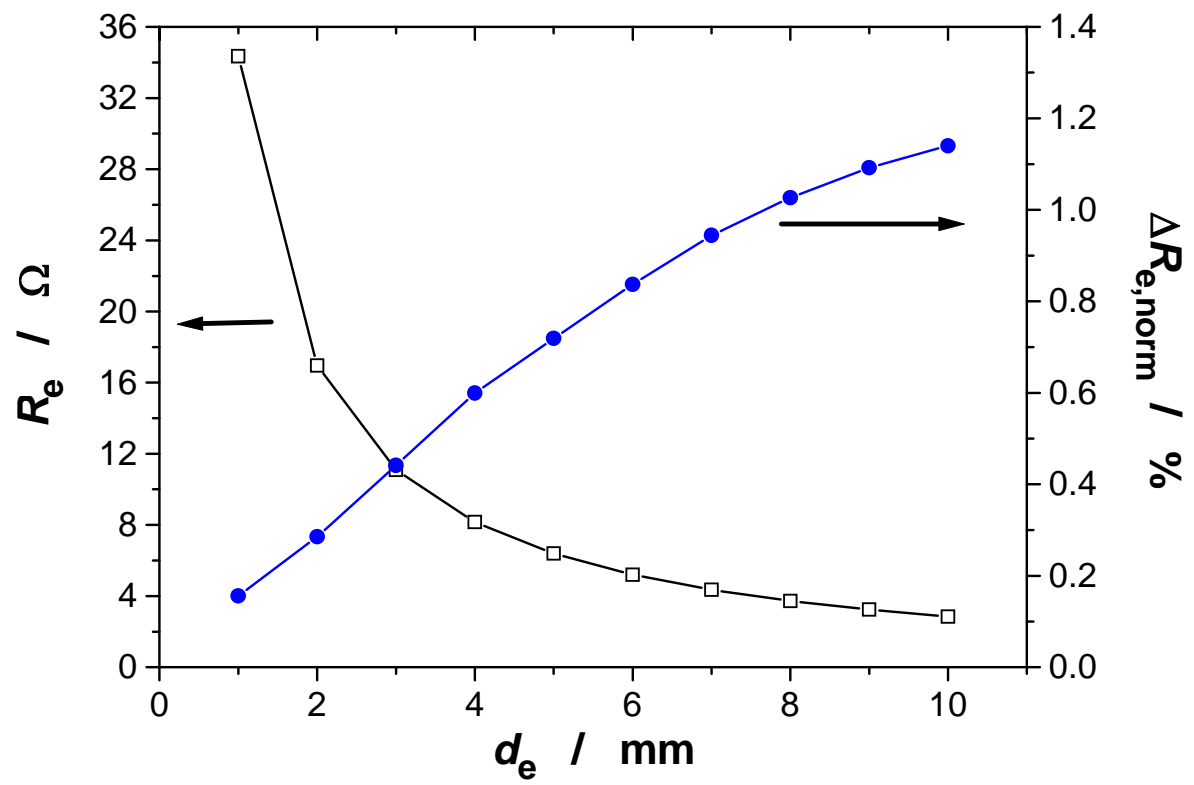

Fig. 7. Variations of $R_{\mathrm{e}}$ and $\Delta R_{\mathrm{e}, \text { norm }}$ as a function of the electrode diameter for an insulating sphere of diameter $d_{\mathrm{p}}=6 \mathrm{~mm}$ centred at $x=y=z=0(\mathrm{D}=20 \mathrm{~mm})$. 

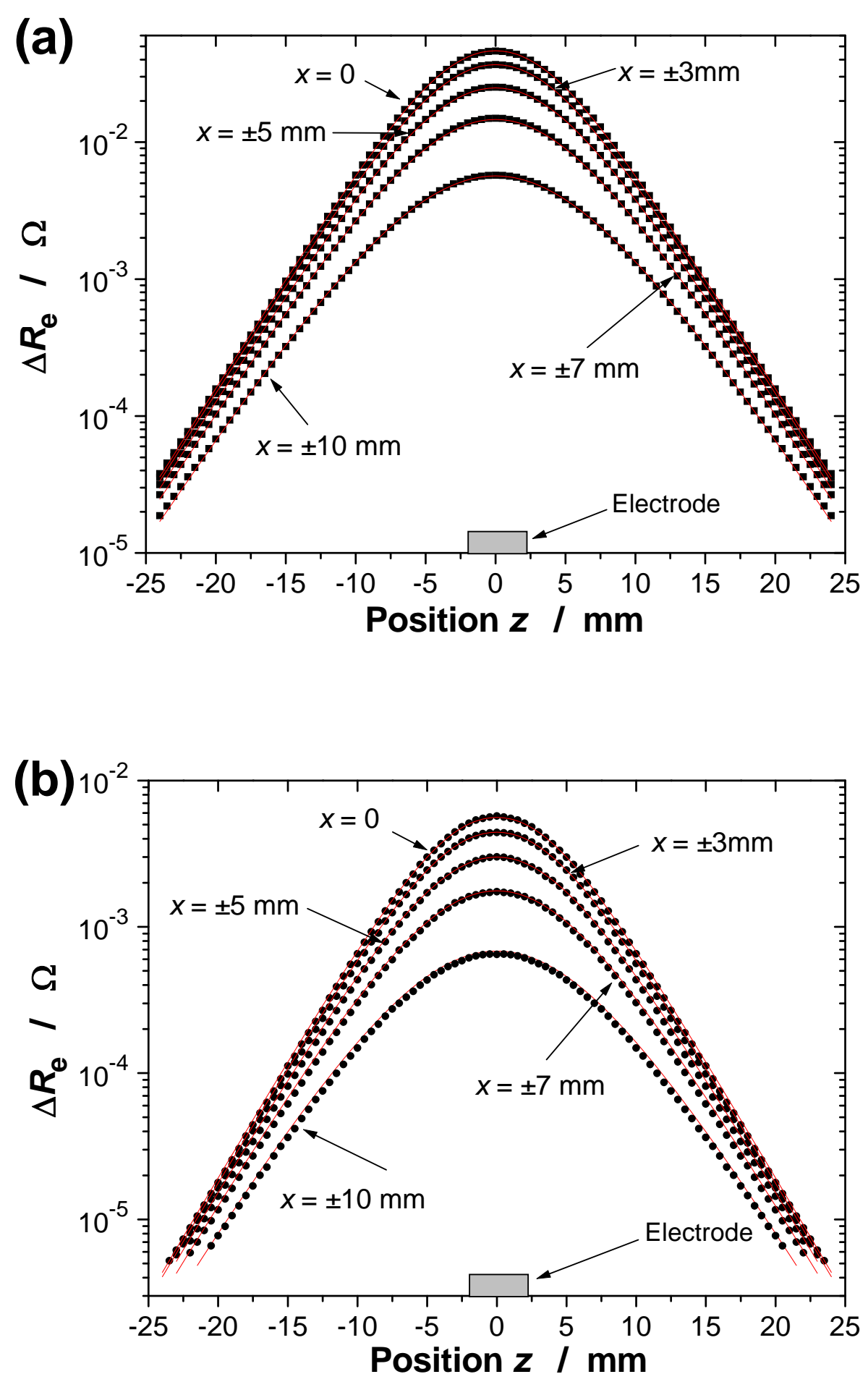

Fig. 8. Values of $\Delta R_{\mathrm{e}}$ as a function of the position of the centre of the insulating sphere along the vertical $\mathrm{Oz}$ axis for $y=0$ and different $x$ values $\left(d_{\mathrm{e}}=5 \mathrm{~mm}, D=20 \mathrm{~mm}\right)$ : (a) $d_{\mathrm{p}}=6 \mathrm{~mm}$, solid red lines obey Eq. 8, (b) $d_{\mathrm{p}}=3 \mathrm{~mm}$, solid red lines obey Eq. 9 . 
Potentiostat

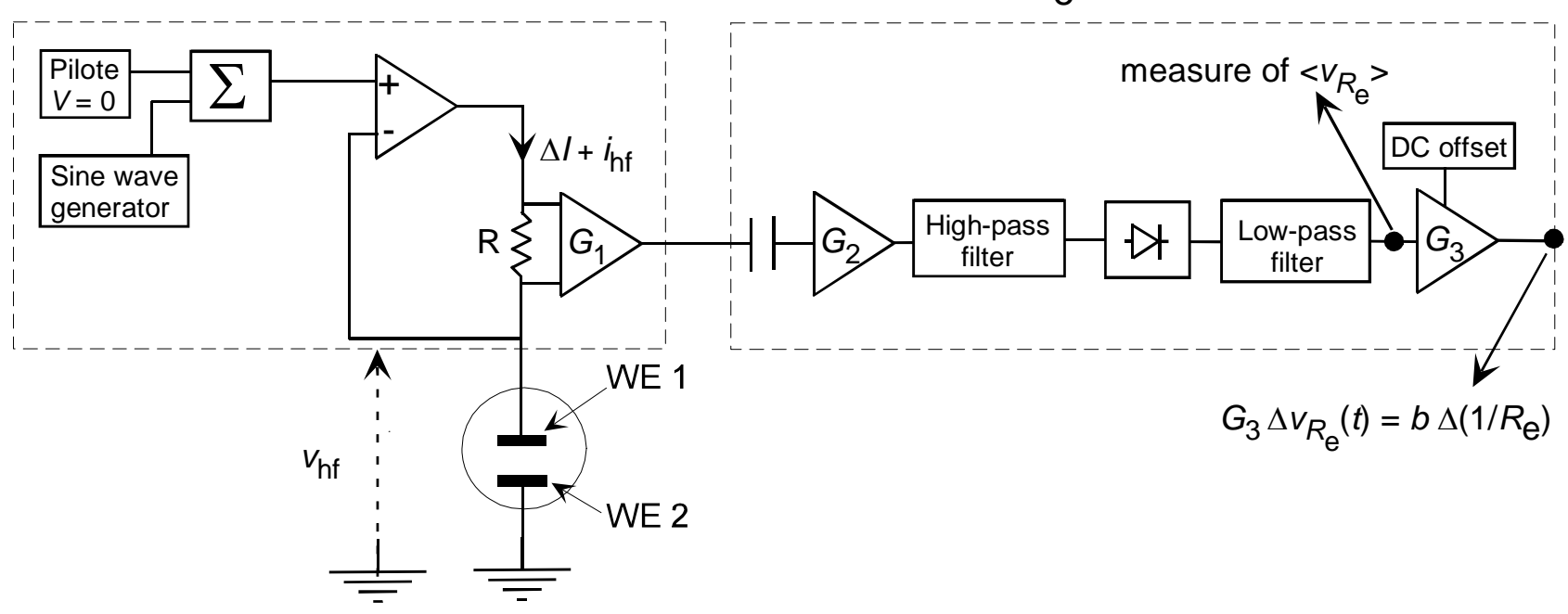

Fig. 9. Experimental setup used for measuring the electrolyte resistance fluctuations due to the passage of insulating spheres between two immerged electrodes. 

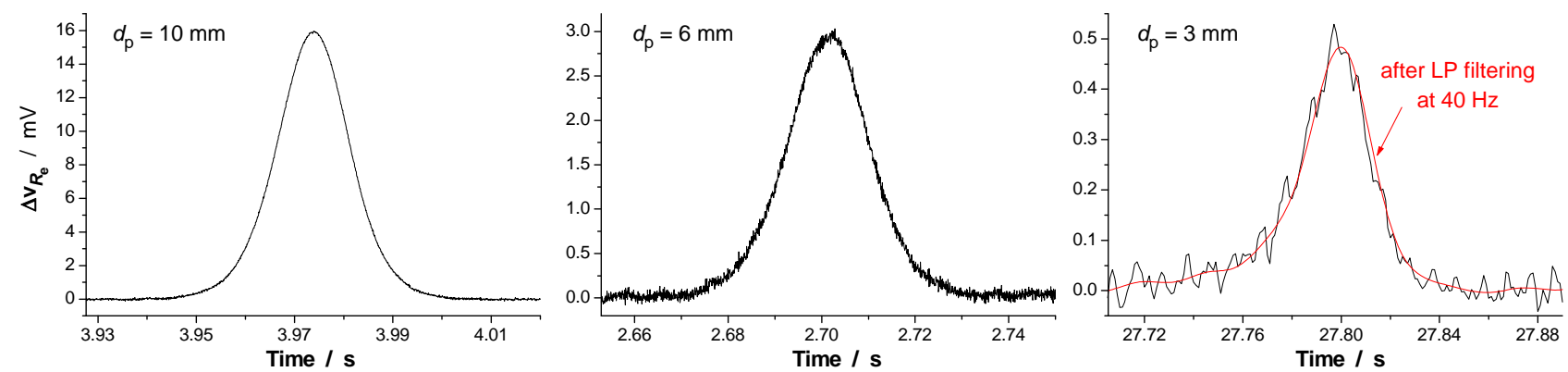

Fig. 10. $v_{R_{\mathrm{e}}}$ variations due to the passage of single insulating spheres of diameter $10 \mathrm{~mm}, 6 \mathrm{~mm}$, and $3 \mathrm{~mm}$ between the electrodes $\left(d_{\mathrm{e}}=5 \mathrm{~mm}, D=20 \mathrm{~mm}\right)$.
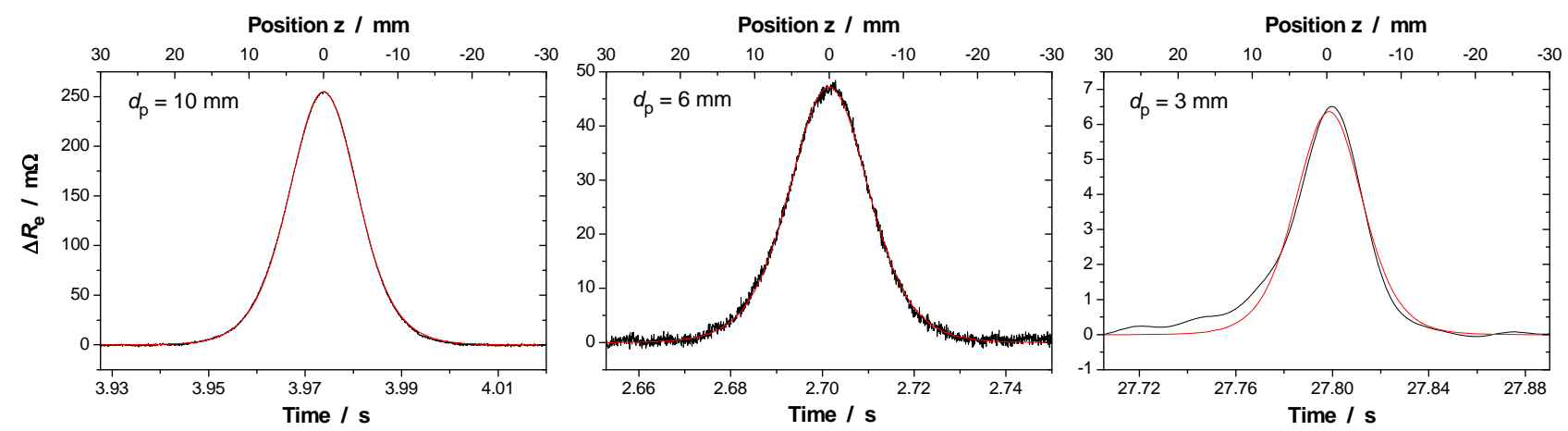

Fig. 11. Experimental (black) $\Delta R_{\mathrm{e}}$ variations corresponding to the $v_{R_{\mathrm{e}}}$ variations shown in Fig. 10 as a function of the sphere position along the $z$ axis. Theoretical curves (red) calculated with Eq. 9 and fitted parameters given in Table 1. 


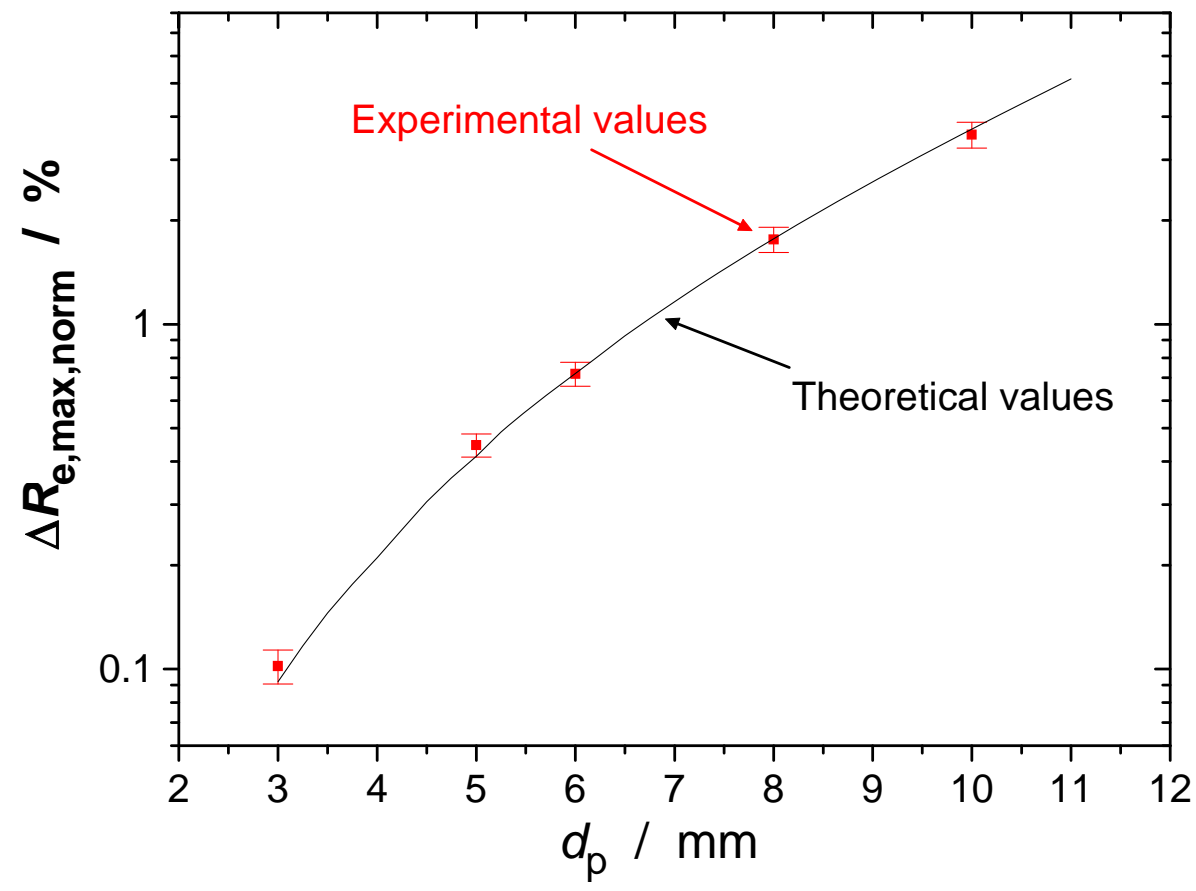

Fig. 12. Experimental and theoretical and values of $\Delta R_{\mathrm{e}, \mathrm{max}, \text {,norm }}$ as a function of the diameter of the insulating sphere centred at $x=y=z=0\left(d_{\mathrm{e}}=5 \mathrm{~mm}, D=20 \mathrm{~mm}\right)$. Error bars indicate twice the standard deviation of 6 sample measurements. 